\title{
NEUROPEDAGOGO NO PROCESSO DE APRENDIZAGEM E INCLUSÃO: UM ESTUDO BIBLIOGRÁFICO
}

\section{ARTIGO ORIGINAL}

ROCHA, Bruna Eduarda ${ }^{1}$, NUNES, Cristiana Padilha², SANTOS, Indiara Padilha Dos ${ }^{3}$, PADILHA, Marindia ${ }^{4}$

ROCHA, Bruna Eduarda. Et al. Neuropedagogo no processo de aprendizagem e inclusão: um estudo bibliográfico. Revista Científica Multidisciplinar Núcleo do Conhecimento. Ano 06, Ed. 06, Vol. 06, pp. 102-116. Junho de 2021. ISSN: 24480959, Link de

acesso: https://www.nucleodoconhecimento.com.br/educacao/neuropedagogo-noprocesso, DOI: 10.32749/nucleodoconhecimento.com.br/educacao/neuropedagogono-processo

\section{RESUMO}

O estudo aqui a ser abordado, trata-se da temática a importância do neuropsicopedagogo para o processo de aprendizagem. Tem como objetivo, discutir o papel do neuropsicopedagogo no processo de inclusão de alunos com deficiência.

${ }^{1}$ Bacharel em Administração - IMED; Licenciatura em Pedagogia - FABE; Especialização em Linguagens e Tecnologias na Educação - IFSUL, Mestranda Programa de Pós-Graduação em Educação da Universidade de Passo Fundo.

${ }^{2}$ Gestão de RH - Uniaselvi, Licenciada Pedagogia - Uniaselvi.

${ }^{3}$ Licenciada em Pedagogia, Especialização em: Educação Especial e Inclusiva e Neuropsicopedagogia Institucional e Clínica.

4 Licenciada em Pedagogia, Especialização em Educação Especial e Inclusiva e Neuropsicopedagogia Institucional e Clínica - Faculdade Futura. Especialização em Práticas Educacionais em Ciências e Pluralidade - UTFPR.

RC: 88288

Disponível em: https://www.nucleodoconhecimento.com.br/educacao/neuropedagogo-noprocesso 
O referencial teórico aborda os seguintes aspectos: Conceitos de neuropsicopedagogia; Diferenças e Importância dos Profissionais; Avaliações e intervenções do neuropsicopedagogo; O neuropsicopedagogo no processo de aprendizagem. Trata-se de um estudo bibliográfico de caráter exploratório. Sendo assim, ao finalizar a pesquisa bibliográfica, foi possível perceber que o processo de aprendizagem é muito mais complexo que ir para a escola e estudar conteúdos, sendo um processo de desenvolvimento que se inicia ainda na educação infantil. Esse processo deve partir do professor, em planejar atividades que desenvolvam o cérebro e corpo da criança.

Palavras-Chave: Neuropsicopedagogo, Criança, Diferenças.

\section{INTRODUÇÃO}

O presente estudo tem como objetivo, tratar a temática neuropsicopedagogia e os processos de inclusão, pois, já não é mais novidade na sociedade em que vivemos, é o foco de congressos, manifestações e estudos. A temática a ser abordada traz a importância do neuropsicopedagogo para o processo de aprendizagem, para realização do estudo verifica-se conceitos de neuropsicopedagogo, analisar o processo de aprendizagem e verificar como o neuropsicopedagogo influencia o processo de aprendizagem.

A importância desta temática reside no fato de que os levantamentos do IBGE (2010) apontam que no Brasil possui milhares de pessoas com necessidades especiais, ou seja, como como está o processo de inclusão desses indivíduos, como as escolas trabalham com essas pessoas, possui profissionais de qualidade para atendê-los? bem como, percebe-se a relevância, pois dentro do espaço escolar, ou não escolar é necessário diferenciar o neuropsicopedagogo clinico, institucional, bem como, a diferença da do psicopedagogo no processo de aprendizagem, saber a função de cada um é relevante para a família, para professores, entre outros incluso na vida humana. Há ainda, notável importância social nesta tratativa, pois se ocupa de

RC: 88288

Disponível em: https://www.nucleodoconhecimento.com.br/educacao/neuropedagogo-noprocesso 
verificar os pontos positivos e negativos da neuropsicopedagogia para a inclusão do, bem como, vem ocorrendo o processo de inclusão no meio social. No mesmo sentido, encontramos notável relevância econômica da pesquisa, pois buscamos identificar as necessidades de maior e melhor investimento quanto ao processo de inclusão.

Com isso, faz-se necessário pensar em uma sociedade tendo a educação como um dos seus pilares mais fortalecidos, onde exigem compromisso com princípios de justiça e de igualdade de oportunidades para todos. Nesse sentido, a educação deve (ou deveria) ser o espaço de que todos possam ter as mesmas oportunidades, mas nem sempre isso acontece porque alguns grupos necessitam de atenção diferenciada e/ou especial.

Ou seja, qualquer diferenciação ou exclusão do indivíduo devido a deficiência é considerado desigualdade, e pessoas com deficiência que sofrem com capacitismo, tem como consequência e desafios, os preconceitos enfrentar os preconceitos vindos da sociedade (MELLO, 2016). É preciso que haja o querer de todos, governantes, sociedade, diretores e coordenadores e até mesmo professores. No entanto, mesmo que protegido por leis, convenções, militâncias justiçais, pessoas com deficiências ainda sofrem por preconceito e discriminação, essas por muitas vezes acontecem ainda quando jovens em período escolar, e no decorrer da vida, é um grande desafio que estes vem tendo, devido ao tipo de deficiência, que se inicia com um simples apelido, até agressões físicas e verbais.

Dentre esses desafios, podemos aqui citar diversos, todos muito relevantes e que para estes não acontecerem, deve-se trabalhar através da educação, ensinar as crianças que não se deve rir, denegrir, ou ferir o outro com palavras e agressões devido, a sua capacidade, cor ou gênero.

No presente trabalho buscou-se discutir alguns elementos, referentes a inclusão de alunos com deficiência e o papel do neuropsicopedagogo para tal processo, bem como até que ponto o processo de inclusão ocorre efetivamente neste espaço. Qual

RC: 88288

Disponível em: https://www.nucleodoconhecimento.com.br/educacao/neuropedagogo-noprocesso 
o papel do neuripsicopedagogo no processo de inclusão escolar? Esses profissionais fazem parte da equipe escolar? As escolas municipais e estaduais têm estruturas para receber crianças com necessidades especiais? Nas escolas há professores capacitados para enfrentar a inclusão de crianças com necessidades especiais? Diante a estes questionamentos e inquietações, surge a questão principal, chamada de problema de pesquisa: Qual a função do neuropsicopedagogo no processo de inclusão e aprendizagem?

Sendo assim, o estudo tem como objetivo geral: compreender a função do neuropsicopedagogo no processo de inclusão e aprendizagem. Tem como objetivos específicos: Conceituar Neuropsicopedagogia; analisar as diferenças e importâncias dos profissionais desta área; verificar quais são as intervenções e avaliações do neuropsicopedagogo; e compreender a importância neuropsicopedagogo no processo de aprendizagem.

Sendo assim, a pesquisa trata-se de um estudo bibliográfico, qualitativa. Para que o estudo seja efetivamente relevante, é necessário a revisão de literatura, a qual nos possibilitará o contato do estudante com situações semelhantes já pesquisadas, bem como, conceitos já trabalhados ou mesmo complementares de certos aspectos do estudo pretendido. Para isso, primeiramente é necessário entender o que o tema aborda, bem como, entender os conceitos de neuropsicopedagogia, diferenças entre elas e a importância da mesma para o processo de aprendizagem da criança, sendo assim, o estudo é dividido em seções.

\section{CONCEITOS DE NEUROPSICOPEDAGOGIA DIFERENÇAS E IMPORTÂNCIA DESTES PROFISSIONAIS}

A neuropsicopedagogia tem como objetivo estudar os sistemas neurológicos e nervoso em prol a aprendizagem, deste modo, está ligada com bases neurobiológicas da aprendizagem, conhecimentos pedagógicos e da psicologia, auxiliando os alunos, ou seja:

RC: 88288

Disponível em: https://www.nucleodoconhecimento.com.br/educacao/neuropedagogo-noprocesso 
[...] uma ciência transdisciplinar nos conhecimentos da Neurociências aplicada à educação, com interfaces da Pedagogia e Psicologia Cognitiva que tem como objeto formal de estudo a relação entre o funcionamento do sistema nervoso e a aprendizagem humana numa perspectiva de reintegração pessoal, social e educacional. (SBNPp, 2020).

A neuropsicopedagogia pode fazer suas intervenções pedagógicas clínicas ou institucional, ou seja, no consultório particular ou no ambiente escolar, quando a intervenção acontece no ambiente escolar, tem uma grande relevância, pois, observará de forma direta, comportamentos, práticas e o processo de aprendizagem do indivíduo.

A neuropsicopedagogia faz parte do campo de conhecimento que divide de forma equilibrada, informações com outros campos, ou seja, Antropologia, Pedagogia, Sociologia, Psicologia, entre outros, auxiliando na construção de conhecimento do indivíduo e na aprendizagem significativa, partindo do desenvolvimento cognitivo e de competências, a neurociência anda junto com outros saberes e ciências, complementando os conhecimentos (FONSECA, 2014).

Para Moreira (2020), a neuropsicopedagogia tem uma visão mais ampla com conhecimentos fundamentados da neurociência $e$ indiferente de ser neuropsicopedagogo clínico ou institucional, os dois contribuem para o processo de aprendizagem, bem como, para formação de professores.

Portanto, o neuropsicopedagogo, é o especialista avaliar e intervir nas questões de transtornos, síndromes e potencialidades no âmbito da aprendizagem, para essa intervenção é necessário um diagnóstico preciso.

Sendo assim, o principal objetivo da neuropsicopedagogia é conhecer e estudar questões do cérebro e seus comportamentos pois, o "cérebro manda e o corpo obedece", então é importante conhecer cada área cerebral e a produção de comportamento do indivíduo, para então avaliar, analisar e intervir nestas.

RC: 88288

Disponível em: https://www.nucleodoconhecimento.com.br/educacao/neuropedagogo-noprocesso 
[...] a neuropsicopedagogia procura reunir e integrar os estudos do desenvolvimento, das estruturas, das funções e das disfunções do cérebro, ao mesmo tempo que estuda os processos psicocognitivos responsáveis pela aprendizagem e os processos psicopedagógicos responsáveis pelo ensino (FONSECA, 2014, p.1).

Sabemos que há diversos profissionais responsáveis pelo desenvolvimento humano, iniciando pela família, seguindo pela escola com os pedagogos e continuando com especialistas que fazem interferências mais específicas para tal desenvolvimento.

Sendo assim, o pedagogo é que irá trabalhar diretamente na educação, na escola, sendo ele professor, e desenvolvendo o processo de aprendizagem da criança, é ele que vai direcionar o aluno para a sua formação. Deste modo, o pedagogo é "A pessoa que se forma em pedagogia entende os processos de ensino-aprendizagem. Aprende também métodos de ensino, de modo que o pedagogo disponha dos conhecimentos de vários métodos de ensino para que a aprendizagem da turma ou do indivíduo" (CASTRO, 2019, p. 1).

Já o psicopedagogo, ou psicopedagogia, é o que vai interferir na pedagogia, ou outras áreas do conhecimento, o mesmo também está ligado ao processo educacional, mas especificamente na aprendizagem.

Cabe ao professor observar algo diferente no seu aluno e pedir que o psicopedagogo também faça essa observação para uma possível intervenção, esta intervenção pode acontecer de forma individual ou no grande grupo. Ainda para Castro $(2019$, p.1)

Quando uma pessoa apresenta dificuldade em aprender um determinado conteúdo, tendo ou não passado por intervenção pedagógica, o psicopedagogo é o profissional que vai investigar a causa desse obstáculo à aprendizagem (dificuldade, transtorno, etc) para então encontrar a melhor forma de intervir de modo que essa pessoa retorne ao seu processo de aprendizagem normal.

A diferença deve ser respeitada pois essa se torna um desafio para quem vive, quando falamos da palavra desafio, neste contexto, trata-se de uma luta a ser vencida, devido 
a algumas situações de impedimento. É ir além das competências e passar por cima de questões diversas que interfiram na vida do ser humano (DICIO, 2021).

Um dos grandes desafios encontrados por pessoas com dificuldades, ou deficiência é a discriminação, qualquer diferenciação ou exclusão do indivíduo devido a deficiência é considerado desigualdade, e pessoas com deficiência que sofrem com capacitismo, tem como consequência e desafios, enfrentar os preconceitos vindos da sociedade (MELLO 2016). Diante ao exposto em 2006 a ONU realizou a Convenção Internacional sobre os direitos das pessoas com deficiência, que se tornou um marco para muitos militantes os quais demandaram justiça pelas pessoas com deficiência ao longo da história. (ONU, 2006)

Neste contexto, foi acordado na convenção aspectos sobre diretos humanos assegurados às pessoas com deficiências. Dentre eles estão questões sobre invisibilidade, inter-relação e interdependência de pessoas com deficiências (BRASIL, 2009). De acordo com a Convenção Internacional sobre os Direitos das Pessoas com Deficiência:

\begin{abstract}
Discriminação por motivo de deficiência" significa qualquer diferenciação, exclusão ou restrição baseada em deficiência, com o propósito ou efeito de impedir ou impossibilitar o reconhecimento, o desfrute ou o exercício, em igualdade de oportunidades com as demais pessoas, de todos os direitos humanos e liberdades fundamentais nas esferas política, econômica, social, cultural, civil ou qualquer outra. Abrange todas as formas de discriminação, inclusive a recusa de adaptação razoável (BRASIL, 2009, p.1).
\end{abstract}

No entanto, mesmo que protegido por leis, convenções, militâncias justiçais, pessoas com deficiências ainda sofrem por preconceito e discriminação, essas por muitas vezes acontecem ainda quando jovens em período escolar, e no decorrer da vida, é um grande desafio que estes vem tendo, devido ao tipo de deficiência, que se inicia com um simples apelido, até agressões físicas e verbais.

RC: 88288

Disponível em: https://www.nucleodoconhecimento.com.br/educacao/neuropedagogo-noprocesso 
Neste sentido, o primeiro desafio que pode ser citado é o respeito e o ato de empatia, muitas pessoas não respeitam, não se colocam no lugar do outro, acabam por julgar, olhar de forma diferente, colocando como incapazes, portanto a um alerta a ser feito "é importante respeitar o consentimento das pessoas com dificuldades indiferente se ela é uma deficiência, um transtorno ou uma simples falta de atenção, perguntando se pode ajudar, se a pessoa precisa de ajuda" (MALAR, 2020, p. 1).

Portanto, o professor deve intervir em questões como essas, parando com a discriminação, observando o aluno, para então se necessário encaminhando-o para um psicopedagogo ou neuropsicopedagogo, que terão funções parecidas, o neuropsicopedagogo também poderá intervir no processo de aprendizagem do aluno como demais transtornos, porém, o mesmo terá mais funções, voltadas a análise do cérebro, bem como questões biológicas.

O neuropsicopedagogo após avaliação e intervenção pode solicitar exames cerebrais, bem como, fazer uma análise e um acompanhamento por determinado tempo, com intuito de melhorar o processo de aprendizagem, o mesmo pode diagnosticar e receitar medicações ao indivíduo se necessário.

Este profissional, pode ser clínico ou institucional, o clínico vai atender apenas a criança e sua família no consultório, procurando avaliar todos os passos, rotina da criança para um melhor diagnóstico, ele também fará a parte institucional, que é na escola a observação da criança no grande grupo, e o seu comportamento no processo escolar de aprendizagem. Diante ao exposto, o próximo tópico, irá abordar de forma específica a importância do Neuropsicopedagogo no processo de inclusão.

\subsection{AVALIAÇÕES E INTERVENÇÕES DO NEUROPSICOPEDAGOGO}

Para que haja uma avaliação e intervenção do neuropsicopedagogo, é necessário que haja um amplo estudo do indivíduo, inicialmente acontece a observação do professor,

RC: 88288

Disponível em: https://www.nucleodoconhecimento.com.br/educacao/neuropedagogo-noprocesso 
e da família, para então a análise do psicopedagogo, é ele quem vai analisar observar e avaliar se necessita da intervenção do neuropsicopedagogo.

Portanto, cabe ao neuropsicopedagogo ir até o ambiente escolar, observar a criança, verificar se realmente é a sua intervenção que irá auxiliar a criança, para então começar as intervenções.

Segundo PUC-RIO (2010), as avaliações são distintas e muito importante, inicia-se com o histórico da vida do indivíduo, para verificar onde o problema se iniciou, posteriormente ele irá analisar o histórico médico do seu paciente se possui alguma alteração neurológica, isso se dá com exames específicos do cérebro.

Posteriormente, se dá a avaliação conduta, que é a observação diária da criança, uma conversa com ela, bem como, a aplicação de testes, voltadas ao desenvolvimento cognitivo, para assim, fazer a análise, está por sua vez trata-se de,

\begin{abstract}
a análise qualitativa na avaliação neuropsicológica envolve categorias que a quantificação não engloba e nem dá conta. Sendo assim, durante a avaliação neuropsicológica e ao analisar os resultados, o profissional deve se respaldar numa teoria psicológica que ofereça recursos para lidar com fatores emocionais e ambientais que afetam o comportamento. Tais fatores devem ser constantemente ponderados diante da necessidade de uma atividade avaliativa, sob pena de reduzir o processo a uma ótica limitada, apresentando apenas os resultados dos testes (PUC-RIO, 2010, p. 61-62).
\end{abstract}

Ainda para PUC-RIO (2010), é importante testes complementares, bem como, conversas com o grupo familiar e análise de comportamento da criança em casa. Por fim, se faz a análise de grupo-controle, que se dá do problema e de tudo que o vem acompanhando, a observação no grupo escolar, a observação no grupo familiar e assim por diante.

Sendo assim, percebe-se que a análise é bem complexa, é um conjunto do sistema funcional dos processos mentais, do ponto de vista cerebral e suas funções e 
complementações. Após essa complexa análise e faz a intervenção, a mesma pode acontecer de diferentes formas.

Para intervenção a partir do diagnóstico, é necessário traçar um plano, o qual irá tratar a criança dependendo do seu "problema", essas intervenções devem ser distintas, pois cada pessoa é um caso, cada cérebro age de uma forma que é diferente dos demais, assim, cada diagnostico terá um tratamento. Segundo Moreira (2020), uma criança é diferente da outra, sendo assim ao observar as dificuldades sendo ela na aprendizagem, motora, na fala é importante procurar um profissional, pois quando é percebido precocemente, é feito o diagnóstico e seguido com o tratamento, quando antes melhor.

Deste modo, segundo Lima (2017), a intervenção deve acontecer de forma conjunta, onde neuropsicopedagogo, família e escola devem trabalhar de forma unida para a resolução de tal problema.

\begin{abstract}
A intervenção neuropsicopedagógica contribuirá para a melhoria na ação do professor e na aprendizagem da criança. Ambas devem ser dinâmicas e próximas da realidade, fazendo com que teoria e prática se firmem e tenha sentido para o sujeito que aprende, de maneira articulada e simultânea, buscando, através da exploração de diferentes atividades, desenvolver as habilidades necessárias, promovendo a descoberta e a inserção da criança no mundo, sem que sofra nenhuma marginalização social (FAVENI, 2020, p. 6).
\end{abstract}

Sendo assim, percebe-se que a intervenção do neuropsicopedagogo, se dá a partir de metodologias e mediação docente e mediação do próprio neuropsicopedagogo, cada caso possui intervenção diferente, ele irá fazer um acompanhamento direto com o aluno, auxiliará o professor nas metodologias de aprendizagem, primeiramente se faz essa intervenção e se a mesma não resolver pode ser incluído medicações para auxiliar ainda mais, porém é necessário tentar tudo antes de inserir os medicamentos. Diante ao exposto, o próximo tópico, irá abordar de forma específica a importância do Neuropsicopedagogo no processo de inclusão.

RC: 88288

Disponível em: https://www.nucleodoconhecimento.com.br/educacao/neuropedagogo-noprocesso 


\subsection{A IMPORTÂNCIA DA NEUROPSICOPEDAGOGIA NO PROCESSO DE INCLUSÃO}

Desde muito cedo, as crianças já estão explorando o mundo a fora na busca de compreender o que está a sua volta, cabe o adulto mediar a criança, auxiliando no desenvolvimento do mesmo, em busca da aprendizagem.

A aprendizagem para Vigotsky (1987) é a interação entre o sujeito com foco em um objetivo comum, interagir é comunicar, e a inclusão, faz parte deste processo, quando bebe, a linguagem é a partir da oralidade, gestos, que aos poucos vão assimilando e agregando conhecimentos e aprendizagem até que iniciam-se as primeiras palavras, gerando as funções das linguagens (VIGOTSKY, 1987).

O desenvolvimento humano passa por diferentes estágios, que são divididas em quatro estágios fase sensório-motor: nascimento até cerca de 2 anos, fase préoperatório: de 2 a 7 anos, estágio operacional concreto: de 7 a 11 anos e operações formais 11 ou 12 anos em diante (PIAGET, 1976 apud FREITAS, 2000).

Desse modo, trabalhar a educação especial e inclusiva no processo educacional é muito importante, pois o processo educacional e uma das fases da vida humana. A inclusão é essencial e de extrema importância para quem está sendo incluso. É um processo difícil, mas de extrema importância, desde a educação infantil e todo o ensino básico e superior.

Como já visto nos tópicos acima, o processo de inclusão vem sendo muito discutida atualmente, mas antes de tratar da inclusão deve-se questionar sobre o diagnóstico das deficiências, muitas crianças precisam passar por um processo de acompanhamento e percepções para então necessitar do neuropsicopedagogo. Sendo assim para Schneider (2019, p. 2):

Neuropsicopedsgogia, é um campo do conhecimento que compartilha de modo harmonioso com outros conhecimentos e princípios de

RC: 88288

Disponível em: https://www.nucleodoconhecimento.com.br/educacao/neuropedagogo-noprocesso 
diferentes elementos das Ciências Humanas: Psicologia, Pedagogia, Sociologia, Antropologia, entre outras, compreendendo o erro apresentado pelo sujeito na técnica de construção do seu conhecimento, de uma aprendizagem significativa e suas interações como razões relevantes no desenvolvimento das competências cognitivas. Ou seja, neurociência anda junto com outros saberes e ciências, complementando os conhecimentos.

Portanto, são situações que irão se criando no processo pedagógico, que nem o professor, psicólogo ou pedagogo irá resolver, são questões que irão tornar-se prática, fácil e muitas vezes solucionadas através do acompanhamento do neuropsicopedagogo.

Desta forma é possível perceber que este profissional, pode auxiliar no processo de inclusão de alunos com alguma deficiência, através da aprendizagem significativa e na aquisição de novos conhecimentos.

Desta maneira, o profissional da Neuropsicopedagogia apropria-se de um papel de extrema importância na abordagem do enigma da dificuldade de aprendizagem de crianças em idade escolar. As dificuldades encontradas durante esse período são esperadas, entretanto necessitam ser supridas, fazendo-se necessárias algumas intervenções distintas das normalmente utilizadas quando a criança apresenta alguma dificuldade (SCHNEIDER, 2019, p. 2).

Portando a neurociência é de grande relevância no processo de aprendizagem, pois o profissional irá utilizar de ferramentas das quais se pesquisa diferentes aspectos do sistema nervoso do indivíduo, procurando formas de aperfeiçoar as aprendizagens educacionais (SCHNEIDER, 2019).

Para o processo de acompanhamento com o neuropsicopedagogo, inicialmente 0 indivíduo ou criança vai até o consultório, cabe ao profissional verificar a necessidade do indivíduo, através do conhecimento familiar e individual do paciente, através de uma entrevista, para então o profissional traçar seus objetivos e trabalhos com o paciente, muitas vezes é necessário traçar objetivos para a família (GOMES, 2020).

RC: 88288

Disponível em: https://www.nucleodoconhecimento.com.br/educacao/neuropedagogo-noprocesso 
"A escuta nos leva a pensar que, como sintoma, esse não aprender resistente pode estar traduzindo conflitos intrapsíquicos construídos nas relações intersubjetivas, particularmente dentro da dinâmica familiar contemporânea (GOMES, 2020, p. 2)”.

Portanto, para qualquer ação necessita de um diagnóstico geral e bem aprofundado, desde a família, seguindo da escola e desempenho da criança, verificando as dificuldades da criança, para então realizar o plano individual (GOMES, 2020).

É notável a importância do neuropsicopedagogo no processo de inclusão, pois o mesmo irá fazer um trabalho completo, visando estimular áreas do cérebro do aluno, bem como auxiliá-lo no processo de aprendizagem, procurando um progresso e avanço da criança com o decorrer do tempo, pensando sempre na formação do aluno dentro do tempo previsto. Diante ao exposto, o próximo tópico, irá abordar de forma específica a importância do neuropsicopedagogo nas intervenções escolares e no processo de aprendizagem.

\subsection{NEUROPSICOPEDAGOGO NO PROCESSO DE APRENDIZAGEM}

A educação básica é o nível de ensino para a formação escolar ela é formada por Educação infantil creche: 0 a 3 anos pré-escola 4 a 5 anos, anos iniciais que se dá do $1^{\circ}$ ao $5^{\circ}$ ano do ensino fundamental anos finais do $6^{\circ}$ ao $9^{\circ}$ ano do ensino fundamental e o ensino médio que e dá do $1^{\circ}$ ao $3^{\circ}$ ano.

A educação infantil tem um papel de grande importância na formação global do indivíduo, os primeiros anos de vida são de fundamental importância para o desenvolvimento imediato da criança. Nesta fase a criança necessita de um desenvolvimento voltado para a psicomotricidade, que é responsável pelo desenvolvimento motor da criança. Portanto novas construções psicomotoras devem ser integradas e experiências motoras adquiridas e adaptadas.

RC: 88288

Disponível em: https://www.nucleodoconhecimento.com.br/educacao/neuropedagogo-noprocesso 
O Ensino Fundamental, faz parte do ensino básico regular, é a passagem da educação infantil para o ensino fundamental, sendo assim, é importante que para o processo de ensino e aprendizagem sejam realizadas atividades que envolvam a exploração do corpo e movimento na escola, com foco no desenvolvimento da escola.

É principalmente nestas etapas que o neuropsicopegagogo irá interferir, pois, quando mais cedo melhor para o diagnóstico e tratamento, quando se trata do processo educacional de aprendizagem é muito importante e deve ser muito específica.

\begin{abstract}
O processo de ensino e aprendizagem a crianças com dificuldades de aprendizagem na pré-escola deve estar pautado numa perspectiva de mudança, de transformação social, no respeito as diversidades de raça, classe, gênero ou qualquer outra distinção, como forma de legitimar um fazer pedagógico democrático. $O$ ensino como construção social, precisa contribuir para a formação integral do ser humano, em seus aspectos físicos, motores, cognitivos, psicológicos, entre outras dimensões (LIMA, 2017, p. 91).
\end{abstract}

Sendo assim, o desenvolvimento humano se dá através de diferentes fases, sensóriomotor, pré-operatório, operações concretas e operações formais a Inteligência é definida por dois aspectos, sendo, a Organização e a adaptação, para assim acontecer a assimilação e acomodação (FAVENI, 2020).

Deste modo, é possível analisar diversas etapas da formação da criança, a partir da idade e dos seus movimentos e desenvolvimentos adquiridos e possível perceber se há ou não a dificuldade no processo de aprendizagem.

Sendo assim, vale observar as características motoras, locomotoras, não locomotoras, manipulativos, ou seja, habilidades físicas, movimentos criativos, imitação, discriminação, naturalidade, movimentos e atividades de dança, imagem corporal, coordenação, entre outras (FAVENI, 2020).

Então, a partir do conhecimento e aplicação de neurociências na sala de aula se podem desenvolver estratégias de ensino para lidar com alunos dislexos e com necessidades especiais, criando assim grandes oportunidades de ensino para essas populações diferenciadas e

RC: 88288

Disponível em: https://www.nucleodoconhecimento.com.br/educacao/neuropedagogo-noprocesso 
consequentemente fazendo uma ponte entre a neurociência e uma nova modalidade de ensino (FAVENI, 2020, p.24).

O cérebro que vai processar a aprendizagem e a aprendizagem e a educação estão diretamente ligadas ao cérebro, sendo assim, além de conhece este processo é necessário elaborar atividade que estimulem os neurônios a formar novas sinapses, bem como, estímulos do motor, da coordenação, por parte do professor e do neuropsicopedagogo para que não seja necessário a intervenção a partir de medicamentos.

Ou seja, o processo de aprendizagem precisa ser muito bem inserido na escola, e quando necessitar de um neuropsicopedagogogo é importante que o professor peça o auxílio a mais cedo possível, pois quanto antes se inicia um tratamento, melhor resultado terá.

\section{CONCLUSÃO}

Ao finalizar a pesquisa bibliográfica, foi possível perceber que o processo de aprendizagem é muito mais complexo que ir para a escola e vencer conteúdos, é sim um processo de desenvolvimento que se inicia ainda na educação infantil, esse processo deve partir do professor, em planejar atividades que desenvolvam cérebro e corpo da criança.

Pensando em inclusão de estudantes com deficiência é inevitavelmente confronto com ramificações relativamente repentinas e incoerentes em semelhança ao idealizar a educação usa-se um ponto de vista exclusivo. Nota-se que há sim diferenças especificas de um pedagogo, de um psicopedagogo e um neuropsicopedagogo, porém, todos devem trabalhar de maneira unida, um complementando o outro e pensando sempre no melhor do seu aluno/paciente.

RC: 88288

Disponível em: https://www.nucleodoconhecimento.com.br/educacao/neuropedagogo-noprocesso 
Portanto, o neuropsicopedagogo seja ele, clinico ou institucional, devem ter em mente o comprometimento da aprendizagem e em ações que realmente inclua o aluno e não o exclua, principalmente quando se trata do ambiente escolar.

É possível afirmar que para acontecer a intervenção de um neuropsicopedagogo, é necessária uma boa avaliação, a que não se detém de um ou dois dias de acompanhamento, e sim de uma observação complexa de um todo, de exames, de rotina, de família e de escola. Sendo assim, cabe ao neuropsicopedagogo ver cada individualidade do paciente, este olhar se difere do escolar, do professor, a escola vai ter um olhar voltado a interação e comunicação do aluno, e o profissional, terá o olhar individual do aluno, pensando no progresso do mesmo.

É importante fazer todas as intervenções possíveis educacionais e familiar, para que não seja necessário o uso de medicamentos quando se trata de aprendizagem, por isso é ainda mais importante que a família e escola sigam todos os processos solicitados pelo neuropsicopedagogo.

Entende-se que a neurociência veio para contribuir ainda mais para o desenvolvimento da aprendizagem ela que vai definir tratamentos para dificuldades, transtornos e até mesmo no processo de aprendizagem. Seria de grande valia se todas as escolas tivessem um neuropsicopedagogo presente no dia a dia, pois, ali ele teria como observar as turmas, os comportamentos das crianças, bem como, a forma em que o professor aborda suas atividades, podendo os auxiliarem.

Por fim, não existe profissional melhor ou pior ou mais importante cada um tem seu papel no processo de educação e da inclusão, iniciando no interesse da família em incluir o filho e seguindo por professores preparados para receber o aluno, bem como, profissionais e neuropsicopedagogo, preparados para verificar a necessidade da criança.

RC: 88288

Disponível em: https://www.nucleodoconhecimento.com.br/educacao/neuropedagogo-noprocesso 
A vista disso, há muitas escolas que tem apenas o professor e diretor, não se tem um acompanhamento de um psicólogo, se um psicopedagogo muito menos de um neuropsicopedagogo.

\section{REFERÊNCIAS}

BOCCATO, V. R. C. Metodologia da pesquisa bibliográfica na área odontológica e o artigo científico como forma de comunicação. Rev. Odontol. Univ. Cidade São Paulo, São Paulo, v. 18, n. 3, p. 265-274, 2006.

CASTRO, T. Pedagogia, psicopedagogia e neuropsicopedagogia: qual a diferença?. 2019. Disponível em< https://tatianecastro.com/2019/08/pedagogiapsicopedagogia-e-neuropsicopedagogia-qual-a-diferenca/>. Acesso em out. 2020.

FAVENI. Avaliação e intervenção - Neuropsicopedaogia. Material Didático AVA. FAVENI 2020. Disponível em<https://ava.faveni.edu.br/wpcontent/uploads/2020/04/AVALIA\%C3\%87\%C3\%83O-E-

INTERVEN\%C3\%87\%C3\%83O-NEUROPSICOPEDAGOGICA.pdf $>$. Acesso em nov. 2020.

FAVENI. Neuroeducação e Fundamentos da aprendizagem. Material Didático AVA FAVENI 2020. Disponível em<https://ava.faveni.edu.br/wpcontent/uploads/2019/07/APOSTILA-NEUROEDUCA\%C3\%87AO-EFUNDAMENTOS-DA-APRENDIZAGEM.pdf> Acesso em nov. 2020.

FONSECA, V. Papel das funções cognitivas, conativas e executivas na aprendizagem: uma abordagem neuropsicopedagógica. Rev. Psicopedagogia 2014; 31(96): 236-53. Disponível em <http://pepsic.bvsalud.org/pdf/psicoped/v31n96/02.pdf>. Acesso em out. 2020.

FREITAS, M.T.A. de. Vygotsky e Bakhtin: Psicologia e Educação: um intertexto. São Paulo: Editora Ática, 2000.

RC: 88288

Disponível em: https://www.nucleodoconhecimento.com.br/educacao/neuropedagogo-noprocesso 
GOMES, M.L. M. Intervenção Neuropsicopedagógica: um Ensaio Sobre a Inclusão Escolar de Alunos com Dificuldades de Aprendizagem. 2020. Disponível em <https://psicologado.com.br/neuropsicologia/intervencao-neuropsicopedagogicaum-ensaio-sobre-a-inclusao-escolar-de-alunos-com-dificuldades-de-aprendizagem> Acesso em jul. 2020.

IBGE - INSTITUTO BRASILEIRO DE GEOGRAFIA E ESTATÍSTICA, 2002. Pesquisa Nacional por Amostra de Domicílios: síntese de indicadores 2001. Rio de Janeiro: IBGE.

LIMA, F. R. Sentidos da intervenção neuropsicopedagógica nas dificuldades de aprendizagem na pré-escola. EDUCA - Revista Multidisciplinar em Educação, v.4, n.7, p. 78-95, jan/abr, 2017-ISSN: 2359-2087. Disponível em<file:///C:/Users/User/Downloads/2012-8432-2-PB.pdf>. Acesso em nov. 2020.

MALAR. J. P. Capacitismo: pessoas com deficiência explicam o que é e como evitá-lo. $\quad$ Estadão $2020 . \quad$ Disponível em $<$ https://emais.estadao.com.br/noticias/comportamento,capacitismo-pessoas-comdeficiencia-explicam-o-que-e-e-como-evita-lo,70003478130>. Acesso em março de 2021

MELLO, A. G. Deficiência, incapacidade e vulnerabilidade: do capacitismo ou a preeminência capacitista e biomédica do Comitê de Ética em Pesquisa da UFSC. Ciência \& Saúde Coletiva, 21(10):3265-3276, 2016. Disponível em $<$ https://www.scielo.br/pdf/csc/v21n10/1413-8123-csc-21-10-3265.pdf>. Acesso em março de 2021.

MOREIRA, N. E. A psicopedagogia e a neuropsicopedagogia na intervenção pedagógica da aprendizagem como ferramenta na formação continuada de professores. $2020 . \quad$ Disponível em<http://www.eventos.ufu.br/sites/eventos.ufu.br/files/documentos/a_psicopedagog 
ia_e_a_neuropsicopedagogia_na_intervencao_pedagogica_da_aprendizagem_com o_ferramenta_na_formacao_continuada_de_professores.pdf> Acesso em out. 2020.

ONU. Convenção da ONU sobre Direitos das Pessoas com Deficiência. 2006. Disponível em <https://fundacaodorina.org.br/a-fundacao/deficienciavisual/convencao-da-onu-sobre-direitos-das-pessoas-com-deficiencia/>. Acesso em março de 2021.

RIO, PUC. Aspectos da Avaliação Neuropsicológica - Complexidade das Funções Cognitivas. Maxwell, [S. I.], p. 1-30, 2010.

SBNPp. Resolução SBNPp n 04 de 04 de maio de 2020, que altera a Resolução 03/2014.

Disponível

em<https://sbnpp.org.br/arquivos/Codigo_de_Etica_Tecnico_Profisisonal_da_Neuro psicopedagogia_-_SBNPp_-_2020.pdf>. Acesso em nov. 2020.

SCHNEIDER, F. Atuação do Profissional da Neuropsicopedagogia no Contexto Escolar. 2019. Disponível em <https://psicologado.com.br/neuropsicologia/atuacaodo-profissional-da-neuropsicopedagogia-no-contexto-escolar> Acesso em jul. 2020.

VIGOTISKI, L. S. Pensamento e linguagem. São Paulo: Martins Fontes, 1987.

Enviado: Março, 2021.

Aprovado: Junho, 2021.

RC: 88288

Disponível em: https://www.nucleodoconhecimento.com.br/educacao/neuropedagogo-noprocesso 